\title{
EVALUASI KONSEP RUANG TERBUKA PUBLIK TERHADAP TINGKAT PELAYANAN PEJALAN KAKI DI KAWASAN JALAN PAHLAWAN SEMARANG
}

\author{
Indah Yuliasari \\ Universitas Indraprasta PGRI, Program Studi Arsitektur \\ yuliasari.wibowo@gmail.com
}

\begin{abstract}
A good public open space is an open space that can accommodate all the activities required by people, both personal and group. Successful public open space can be measured by several success criteria. Every activity always begins and finishes on foot, not supported by the availability of adequate pedestrian paths. These criteria can be easily accessed, interactive, useful, and convenient. These criteria must meet human needs, including persons with disabilities. For people with disabilities, universal design becomes one of the most appropriate design concepts to meet all human needs. Universal design refers to a broad spectrum of ideas, aimed at generating buildings, products and environments that can be generally utilized by everyone without restrictions. In urban areas, universal design is a relatively new thing, therefore the application of universal design in urban areas needs to be evaluated, especially in public open space as one of the urban elements. In this study, researchers want to evaluate the concept of public open space that exist especially in the area of Heroes of Semarang. The purpose of this evaluation is to find flaws in the public open space design process. Public open spaces are selected as research areas because they provide significant social and economic impacts for urban areas. The development of pedestrian paths in this district is the main thing to create a friendly pedestrian area, be able to realize synergistic and solid space systems with each other, also encourage environmentally friendly activities. Roads need to be designed to create safety for all road users.
\end{abstract}

Key Words: pedestrian concept, Pedestrian Friendly

\begin{abstract}
Abstrak : Ruang terbuka publik yang baik adalah ruang terbuka yang bisa menampung semua aktifitas yang dibutuhkan oleh orang - orang, baik yang bersifat personal maupun kelompok. Ruang terbuka publik yang berhasil dapat diukur oleh beberapa kriteria keberhasilan.. Setiap aktivitas selalu dimulai dan selesai dengan berjalan kaki, tidak didukung oleh ketersediaan jalur pejalan kaki yang memadai. Kriteria tersebut diantaranya dapat mudah diakses, interaktif, bermanfaat, dan nyaman. Kriteria tersebut harus memenuhi kebutuhan manusia, termasuk orang-orang disabilitas. Bagi orang-orang disabilitas, desain universal menjadi salah satu konsep perancangan yang sesuai untuk memenuhi semua kebutuhan manusia. Desain universal mengacu pada spectrum ide yang cukup luas, bertujuan untuk menghasilkan bangunan, produk dan lingkungan yang secara umum dapat dimanfaatkan oleh semua orang tanpa batasan. Di area perkotaan, desain universal merupakan sesuatu hal yang relatif baru, oleh sebab itu penerapan desain universal di area perkotaan perlu dievaluasi, terutama pada ruang terbuka publik sebagai salah satu elemen perkotaan. Dalam penelitian ini, peneliti ingin mengevaluasi konsep ruang terbuka publik yang ada khusunya kawasan jalan Pahlawan Semarang. Tujuan dari evaluasi ini adalah untuk menemukan kekurangan dalam proses desain ruang terbuka publik. Ruang terbuka publik dipilih sebagai area penelitian karena memberikan dampak sosial dan ekonomi yang cukup signifikan bagi kawasan perkotaan. Pengembangan jalur pejalan kaki di kabupaten ini adalah hal utama untuk menciptakan kawasan pejalan kaki yang ramah, dapat mewujudkan sinergis dan sistem ruang padat satu sama lain, juga mendorong aktivitas yang ramah lingkungan. Jalan-jalan perlu dirancang untuk menciptakan keselamatan bagi semua pengguna jalan.
\end{abstract}

Kata Kunci : konsep jalur pejalan kaki, Pedestrian Friendly.

\section{PENDAHULUAN}

Aktivitas berjalan kaki merupakan suatu bagian integral dari aktivitas lainnya. Bagi masyarakat di daerah tropis, berjalan kaki mungkin kurang nyaman karena masalah cuaca. Di musim kemarau cuaca panas terik menurunkan jarak berjalan yang masih dapat ditoleransi. Di musim penghujan, potensi hujan deras dapat menyurutkan ketahanan untuk berjalan kaki pada jarak dekat sekalipun. Padahal berjalan kaki merupakan tindakan yang sederhana akan tetapi memiliki peran penting dalam sistem transportasi setiap kota karena hampir setiap aktivitas pergerakan diawali dan diakhiri dengan berjalan kaki. Fungsi utama trotoar adalah untuk 
memberikan pelayanan kepada pejalan kaki sehingga dapat meningkatkan kelancaran, keamanan dan kenyamanan pejalan kaki tersebut. Trotoar juga berfungsi memperlancar lalu lintas jalan raya karena tidak terganggu atau terpengaruh oleh lalu lintas pejalan kaki. Trotoar pada dasarnya adalah ruang khusus pejalan kaki dan setiap fasilitas yang ada di trotoar diperuntukkan pejalan kaki. Pejalan kaki merupakan istilah dalam transportasi yang digunakan untuk menjelaskan orang yang berjalan di lintasan pejalan kaki baik dipinggir jalan, trotoar, lintasan khusus bagi pejalan kaki ataupun menyeberang jalan. Pada dasarnya kinerja lalu lintas pejalan kaki diekspresikan dengan cara yang mirip dengan ekspresi kinerja lalu lintas kendaraan yaitu dengan arus, kecepatan, dan kepadatan yang saling berhubungan. Pejalan kaki berada di puncak piramida transportasi, yang artinya pengguna jalan kaki harus diprioritaskan dalam penggunaan jalan. Karena pejalan kaki merupakan transportasi yang paling murah, bebas polusi, serta berpotensi paling minim sebagai penyebab kecelakaan. Dengan pertumbuhan dan perkembangan jaman, dengan hadirnya pusat perbelanjaan, wisata kuliner dan wisata jalan-jalan dengan berjalan kaki telah menandai perubahan yang signifikan. Salah satu titik dimana merupakan titik kumpul dan tempat bersantai untuk wisata yaitu Jalan Pahlawan Semarang.

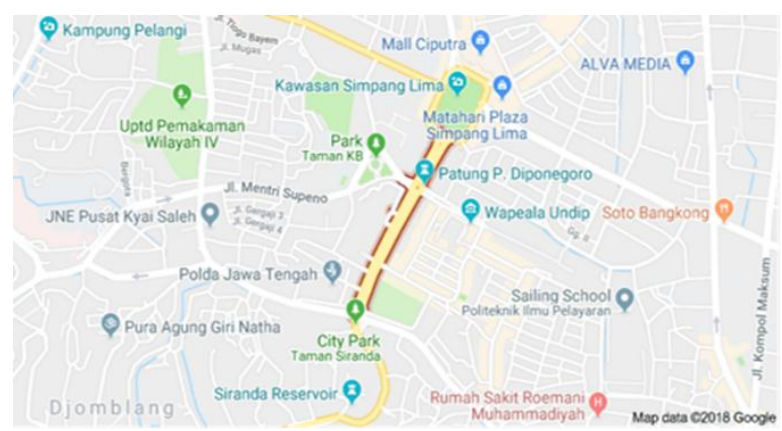

Gambar 1. Peta Lokasi Jalan Pahlawan Semarang

Di hampir sepanjang jalan Pahlawan merupakan areal potensial pejalan kaki, baik yang lewat, beristirahat atau bertransaksi jual beli Setiap harinya area trotoar depan selalu dilalui pejalan kaki dan pedagang. Baik mereka masyarakat sekitar yang sedang melintas atau berdagang ataupun wisatawan. Dan selalu ramai pada hari Sabtu khususnya sore hingga malam dan hari Minggu. Banyaknya pejalan kaki yang melintas di area trotoar jalan Pahlawan, membuat potensi pedagang melakukan jual beli sangat tinggi, hal ini terbukti dengan dominannya pedagang yang berjualan di hari dan jam tertentu. Juga fasilitas pendukung yang ada di area tersebut tersedia dengan baik. Fasilitas pada daerah ini dibagi dua jenis yaitu fasilitas tetap dan tidak tetap. Yang dimaksud fasilitas tetap yaitu fasilitas yang tidak dapat berpindah pindah dan dipindahkan. Sebagai contoh yaitu fasilitas tempat duduk dan tiang bendera. Sedangkan fasilitas tidak tetap yaitu fasilitas yang mampu berpindah ataupun dipindahkan. Sebagai contohnya yaitu tikar tempat berjualan, atau lapak pedagang. Mengingat pejalan kaki merupakan salah satu moda dari transportasi, maka perlu dilakukan penelitian. Atas pertimbangan karena kawasan trotoar Jalan Pahlawan merupakan salah satu titik kumpul dan perlintasan pejalan kaki yang ramai, maka dilakukan penelitian mengenai karakteristik pejalan kaki, tingkat pelayanan trotoar terhadap pejalan kaki, serta tingkat pelayanan trotoar karena pengaruh fasilitas yang ada termasuk pengaruh adanya pedagang yang berjualan. Lingkungan perkotaan yang manusiawi adalah lingkungan perkotaan yang ramah bagi pejalan kaki, yang mempunyai ukuran dan dimensi berdasarkan skala manusia. Upaya ke arah itu dapat dilakukan melalui pengembangan kawasan pejalan kaki serta penyediaan fasilitas pejalan kaki yang memadai di kawasan perkotaan, terutama di kawasan pusat kota Semarang. Hal ini merupakan suatu upaya untuk menciptakan lingkungan perkotaan yang sesuai dengan karakteristik dan tuntutan kebutuhan pejalan kaki dengan tujuan untuk mempertahankan pusat kota agar tetap manusiawi, menarik bagi warga kota untuk datang, tinggal, bekerja, dan melakukan kegiatan lainnya dalam rangka memenuhi kebutuhan jasmani dan rohaninya. Pada Pasal 25 UU Nomor 22 Tahun 2009 disebutkan bahwa "setiap jalan yang digunakan untuk lalu lintas umum wajib dilengkapi dengan perlengkapan jalan berupa fasilitas untuk pejalan kaki dan penyandang cacat". Berdasarkan aspek legal tersebut maka terdapat keharusan untuk menyediakan fasilitas pejalan kaki yang memadai. Setiap orang termasuk penduduk Indonesia adalah pejalan kaki dan berhak untuk menikmati fasilitas pejalan kaki yang layak karena setiap kegiatanyang dilakukan selalu diawali dan diakhiri dengan berjalan kaki. Penyediaan jalur pejalan kaki hampir tidak ditemukan terutama pada sarana-sarana yang ada pada Kawasan jalan Pahlawan Semarang, baik di 
sepanjang koridor jalan arteri maupun lingkungan, sehingga pejalan kaki terpaksa menggunakan bahu jalan sebagai tempat untuk berjalan kaki. Hal ini bertentangan dengan fungsi bahu jalan sebenarnya yaitu tidak diperuntukkan bagi pejalan kaki tetapi sebagai tempat pemberhentian sementara kendaraan atau pada saat darurat bagi kendaraan ambulans sehingga menyebabkan rendahnya tingkat perjalanan pejalan kaki untuk jarak pendek. Oleh karena itu, perlu diidentifikasi alasan masyarakat tidak berjalan kaki untuk jarak pendek ke tujuan (destination), menemu kenali pola jalur/pathway yang dilewati para pejalan kaki di kawasan ini dan mengidentifikasi kondisi eksisting jalur pejalan kaki tersebut dan output yang diharapkan yaitu menyusun arahan pengembangan sebagai solusi permasalahan sehingga tercipta pengoptimalisasian pedestrian dan masyarakat dapat merasa aman, nyaman, dan lancar dalam berjalan kaki di jalan Pahlawan Semarang.

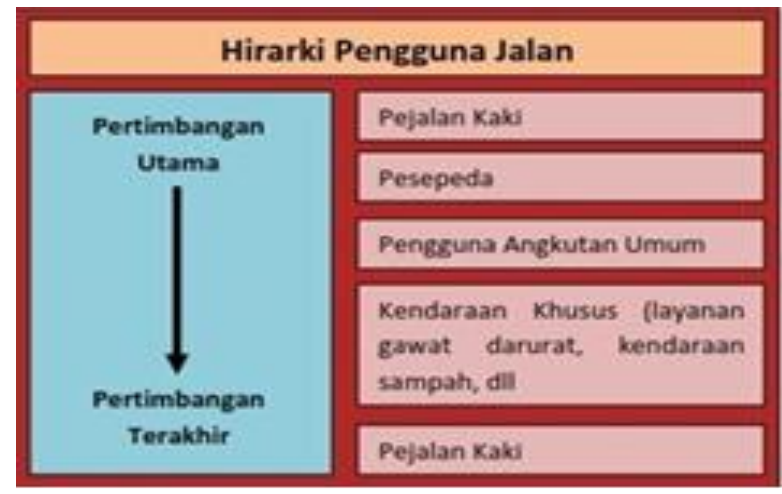

Gambar 2. Hierarki Pengguna Jalan.

Sumber : Komponen Transportasi Perkotaan Pejalan kaki

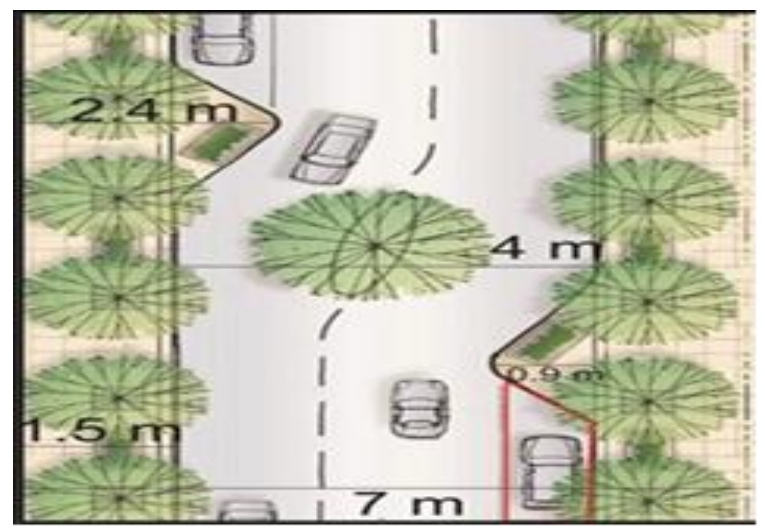

Gambar 3. Arahan PengembanganPenampang Melintang Jalan Lingkungan

Sumber : Hasil Analisis dan Perencanaan Peneliti. 2015

\section{METODOLOGI}

Proses penelitian ini terdiri dari pengumpulan data, penyusunan data, dan analisis data. Output penelitian ini berupa kesimpulan dan rekomendasi untuk arahan pengembangan. Pendekatan penelitian ini menggunakan penelitian lapangan/survey, dilakukan dengan mengunjungi langsung lokasi penelitian. Menurut tingkat explanasinya, merupakan :

- Penelitian deskriptif, mengungkapkan alasan masyarakat tidak berjalan kaki dan mendeskripsikan kondisi eksisting jalur pejalan kaki di lokasi penelitian.

- Untuk memudahkan dalam penulisan penelitian ini maka masalah dibatasi hanya pada jalur pedestrian disekitar Jalan Pahlawan Semarang..

Berdasarkan latar belakang di atas, perumusan masalah sebagai berikut :

1. Bagaimana kondisi jalur pedestrian di sekitar Jalan Pahlawan.

2. Bagaimana pemecahan masalah jalur pedestrian untuk para penyandang disabilitas.

Tujuan dalam penelitian ini adalah sebagai berikut :

1. Mengetahui karakteristik pejalan kaki yaitu arus (flow), kecepatan (speed), kepadatan (denisty), dan ruang (space) di Jalan Pahlawan.

2. Menganalisis tingkat pelayanan (Level of Service) pejalan kaki akibat pengaruh fasilitas trotoar dan pedagang yang ada di Jalan Pahlawan Semarang.

Tujuan dari penelitian ini adalah menyediakan informasi mengenai kondisi fasilitas pejalan kaki dan persepsi pejalan kaki tentang kondisi fasilitas pejalan kaki di beberapa kota di Indonesia, untuk dapat digunakan sebagai masukan pengembangan kebijakan dan desain fasilitas pejalan kaki yang lebih baik. Hasil dari penelitian diharapkan dapat meningkatkan pemahaman masyarakat dan pembuat kebijakan akan pentingnya hak pejalan kaki dan dukungan untuk fasilitas pejalan kaki yang lebih baik, termasuk juga fasilitas untuk pengguna sepeda, kursi roda dan penyandang cacat. Menguraikan hasil analisis kualitatif dengan penekanan pada jawaban atas permasalahan. Pembahasan juga dikembangkan dengan hasil-hasil penelitian sudah ada berikut referensi yang mendukung.

\section{HASIL DAN PEMBAHASAN}

Analisa Jalur Pedestrian

Jalan Pahlawan memiliki fungsi jalan kolektor primer dengan panjang jalan $\mathrm{km}$, 
volume lalu lintas Jalan Pahlawan cukup tinggi dibandingkan jalan lainnya dikota Semarang terutama pada jam sibuk dikisaran waktu 07.0008.00 dengan jenis kendaraan kecil dan sepeda motor. Pengerjaan proyek pedestrian ini dilakukan di sejumlah jalan protokol di Kota Semarang yakni di Kawasan Simpang Lima, Taman KB, Jalan Pahlawan dengan menggunakan keramik tegel unpolis dan batu alam. Pedestrian selebar 2 hingga 5 meter (sesuai kondisi lokasi) ini nantinya juga akan dilengkapi jalur hijau, penerangan, dan jalur bagi para difabel. Di kawasan Taman KB dan Simpang Lima juga terdapat shelter bagi PK Batasan yang diambil yaitu Bundaran SimpangLima sampai perempatan jalan Sriwijaya.

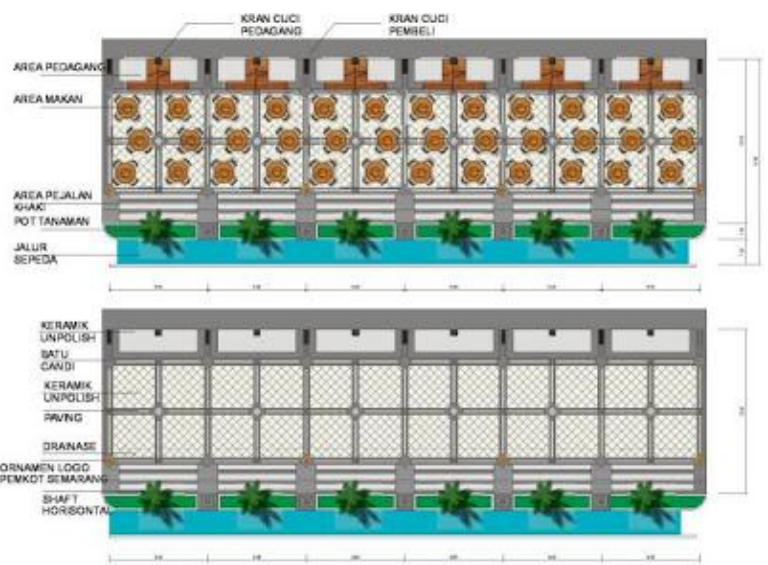

Gambar 4. Konsep Pedestrian

Pedestrian ini mencapai puncak teramai di titik ini adalah pukul 07.00-10.00 WIB dan pukul 16.00-19.00 WIB. Pada titik ini sarana yang tersedia bagi pejalan kaki adalah zebra zross dan trotoar.

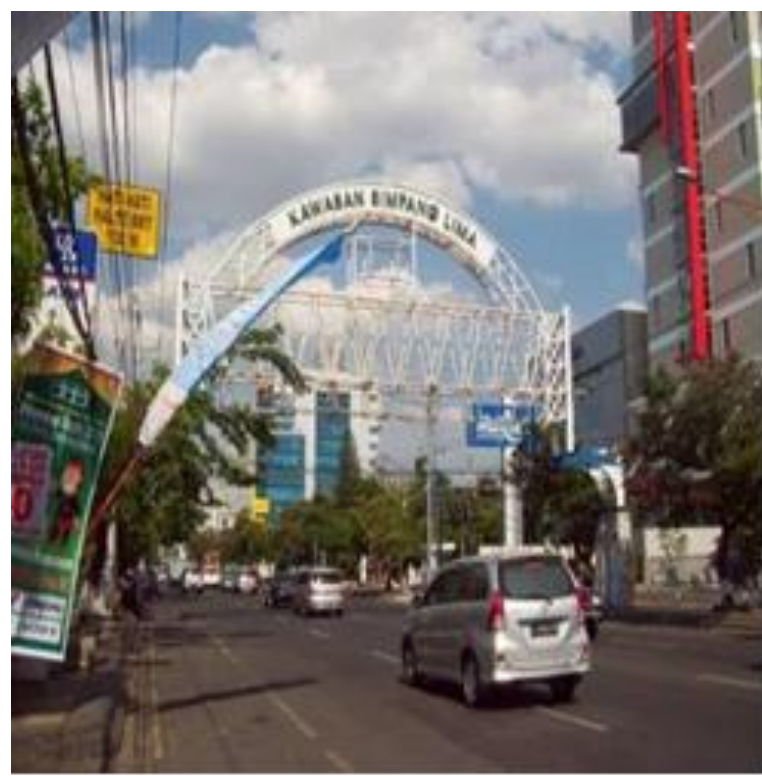

Gambar 5.Situasi jalan siang hari

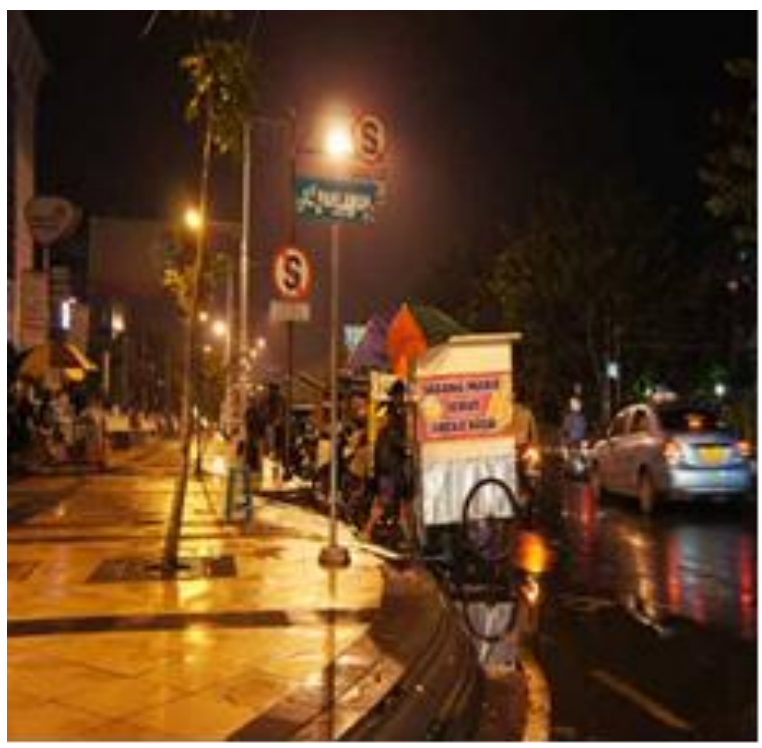

Gambar 6. Situasi jalan malam hari

Pada titik tertentu terdapat tiang atau pohon tepat ditengah trotoar. Kondisi trotoar dan zebra cross yang tidak sesuai dengan kebutuhan dan perilakupelaku jalan ini membuat para pelaku berjalan tidak pada tempatnya sehingga pola perjalanan para pejalan kaki terkesan semrawut. Selain trotoar dan zebra cross, sarana yang tersedia untuk pejalan kaki adalah halte. 

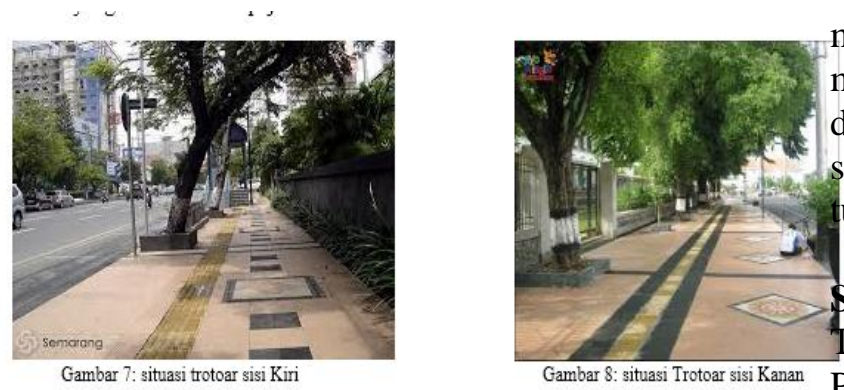

Untuk mengakomodir kebutuhan tersebut, maka perlu disediakan informasi bagi pejalan kaki yang memiliki keterbatasan, meliputi: tanda-tanda bagi pejalan kaki, tanda-tanda pejalan kaki yang dapat diakses, signal suara yang dapat didengar, pesanpesan verbal, informasi lewat getaran, dan peringatan-peringatan yang dapat dideteksi.

Persyaratan untuk rambu dan marka bagi pejalan kaki berkebutuhan khusus agar memperhatikan Peraturan Menteri Pekerjaan Umum No. 30/PRT/M/2006 tentang Pedoman Teknis Fasilitas dan Aksesibilitas Pada Bangunan Gedung dan Lingkungan. Bagi pejalan kaki yang berkebutuhan khusus (tuna netra dan yang terganggu penglihatan), membutuhkan informasi khusus pada permukaan lajur pejalan kaki. Informasi tersebut disebut lajur pemandu. Lajur pemandu terdiri dari:

Ubin/blok kubah sebagai peringatan

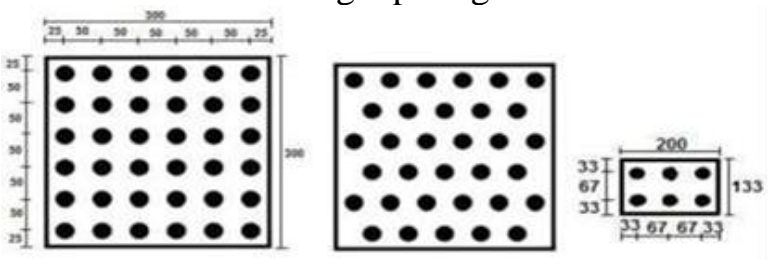

Ubin/blok garis sebagai pengarah.

Jalur ini berupa trotoar yang digunakan bersama-sama oleh pejalan kaki dan pengguna sepeda. Jalur sepeda yang berada di trotoar dapat terletak disebelah kanan ataupun kiri dari jalur pejalan kaki. Penempatan jalur sepeda di trotoar harus tetap menyediakan lebar minimal trotoar bagi pejalan kaki sebesar 1,5 m.

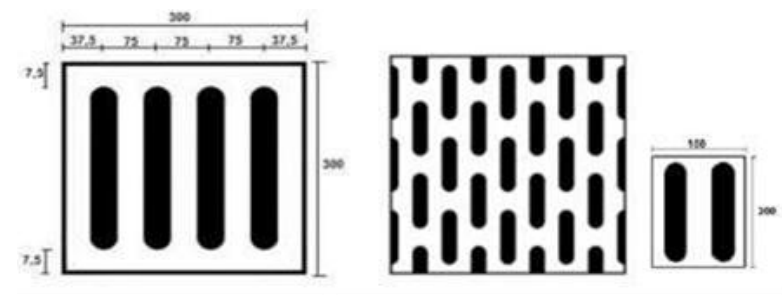

\section{Pengembangan}

Pendekatan Pengembangan berupa pendekatan komprehensif atau menyeluruh yang mempertimbangkan berbagai aspek dan merupakan pendekatan pengembangan yang didasarkan pada rencana makro suatu kota, sehingga arahan pengembangan harus merupakan urunan dari rencana makro kota induknya.

\section{IMPULAN}

Terlihat bahwa kondisi pedestrian di sekitar Jl. Pahlawan Semarang, masih belum memenuhi standar untuk menjadi pedestrian yang mendukung para penyandang disabilitas. Lingkungan perkotaan yang ramah bagi pejalan kaki adalah lingkungan perkotaan yang sangat mendukung para penyandang disabilitas. Upaya ke arah itu dapat dilakukan melalui pedestrianisasi kawasan perkotaan, terutama di pusat kota, yaitu merupakan suatu upaya untuk menciptakan lingkungan perkotaan yang sesuai dengan karakteristik dan kebutuhan pedestrian Berisi berbagai simpulan yang di ambil berdasarkan penelitian yang telah dilakukan. Merupakan pernyataan singkat tentang hasil yang disarikan dari pembahasan. Simpulan dapat berbentuk paragraf namun sebaiknya berbentuk point-point dengan menggunakan numbering. Pemerintah sudah seharusnya melakukan redesain terhadap semua pedestrian bukan hanya untuk mendukung para penyandang disabilitas tetapi untuk meningkatkan keamanan dan kenyamanan bagi setiap pejalan kaki yang menggunakannya. Alasan masyarakat tidak berjalan kaki karena :

a. Lebih memilih menggunakan kendaraan, karena didukung dengan kepemilikan kendaraan (automobile dependency). Hal ini menyebabkan banyaknya hambatan yang terjadi di jalur pejalan kaki yang disebabkan kendaraan roda dua.

b. Cuaca Buruk, yaitu pada saat hujan maupun panas terik, terjadi genangan di jalur pejalan kaki sehingga jalur yang ada tidak terlindung dari cuaca buruk dan menggangu kenyamanan dan kemudahan masyarakat pada saat berjalan kaki.

c. Tidak Suka Berjalan Kaki karena fasilitas berkendara lebih baik daripada fasilitas jalur pejalan kaki sehingga masyarakat lebih memilih/bergantung pada kendaraan. Selain itu, karena banyaknya hambatan dan tidak aman serta tidak mudahnya jalur pejalan kaki.

d. Tidak Terdapat Fasilitas \& Jalur bagi Pejalan Kaki bagi usia muda maupun tua bahkan untuk difable karena kurangnya perhatian pemerintah terhadap penyediaan/pengembangan. 


\section{SARAN}

a. Untuk pemerintah dan stakeholder agar mewadahi dan lebih memperhatikan kebutuhan fasilitas pejalan kaki yang :

- Aman, Pembagian yang jelas antara jalur pejalan kaki dengan kendaraan.

- Nyaman untuk berjalan kaki pada saat cuaca hujan maupun panas terik (urban umbrella, arcade pohon).

- Mudah, perlu penyediaan fasilitas dan penataan jalur pejalan kaki untuk semua usia yang mudah dilewati terutama pada saat terburuburu (bebas hambatan)

- Berdaya tarik, untuk meningkatkan minat berjalan kaki agar terciptanya sistem transportasi yang sustainable untuk masa depan sehingga perlu penataan jalan dan jalur yang mendukung untuk berjalan kaki.

b. Untuk masyarakat yaitu sebaiknya mengurangi penggunaan kendaran khususnya kendaraan roda dua untuk jarak dekat, agar tidak terjadi kemacetan di pusat-pusat kegiatan, tidak bertambahnya hambatan dan polusi, dan untuk menciptakan lingkungan yang ramah pejalan kaki.

c. Untuk peneliti selanjutnya dapat meneliti tingkat ketergantungan masyarakat pada kendaraan.

d. Langkah Pemkot membangun trotoar patutlah dihargai hal ini sesuai Pasal 25 ayat (1) huruf UU LLAJ, akan ttp dalam pelaksanaan terdapat hal yang kurang tepat:

1. Mutu tegel guidance block (jalur pemandu) sangat rendah sehingga cepat rusak.(perlu pengawasan).

2. Penerapan konsep beda elevasi yang besar antara trotoar dengan jalan,dan asumsi pejalan kaki maksimal 2 orang enjadikan trotoar hilang keindahan dan kerapiannya.

3. Konsep tersebut menjadikan trotoar mirip tanggul bila diterapkan pada trotoar yang tidak terlalu lebar serta potongan ke jalan masuk rumah jadi curam.
4. Trotoar seharusnya aman dan nyaman untuk para manula, difabel, ibu dengan kereta bayi, dan bebas halangan, seperti pot besar, tempat sampah, Pedagang Kaki Lima, Pos Polisi, Halte dan sebagainya sesuai pasal 28 ayat (2) UULLAJ dan Pasal 34 ayat $(3,4)$ PP Jalan.

5. Seyogyanya pembangunan trotoar dilaksanakan bersamaan dengan pembenahan saluran drainagenya.

\section{DAFTAR PUSTAKA}

Ashihara, Yoshinobu, 1983, The Aesthetic Townscape, The M.I.T. Press,Cambridge

Budihardjo, Eko dan Djoko Sujarto. 1998. Kota Yang Berkelanjutan. Direktorat Jenderal Pendidikan Tinggi, Departemen Pendidikan Dan Kebudayaan.

Denhardt. 2013. Pelayanan Publik Baru : dari Manajemen Steering ke Serving. Yogyakarta: Kreasi Wacana.

Mulyandari, Hestin. 2011. Pengantar Arsitektur Kota. Yogyakarta : Penerbit Andi.

Natalia Tanan dan Agus Bari Sailendra. Modul Pelatihan: Perencanaan Teknis Fasilitas Pejalan Kaki. Kementrian PU.

Peraturan Walikota Semarang Nomor 17 Tahun 2013 Tentang Rencana Kerja Pembangunan Daerah (RKPD) Kota Semarang Tahun 2014.

Peraturan Daerah Kota Semarang Nomor 14 Tahun 2011 Tentang Rencana Tata Ruang Wilayah Kota Semarang Tahun 2011 - 2031.

Purnomohadi, Ning. 2006. Ruang Terbuka Hijau Sebagai Unsur Utama Tata Ruang Kota. Direktorat Jenderal Penataan Ruang, Departemen Pekerjaan Umum. Jakarta. Rencana Tata Ruang Wilayah (RTRW) Kota Semarang 2010-2030. Bappeda Kota Semarang 